\title{
Cultura e política \\ A criação do Ministério da Cultura na \\ redemocratização do Brasil
}

Fabio Maleronka Ferron*

https://orcid.org/0000-0002-3838-8974

Maria Arminda do Nascimento Arruda*

https://orcid.org/0000-0002-1609-6743

A questão da Cultura na redemocratização

A intenção de criar um ministério específico para o setor da cultura, independente da Educação, intensificou-se a partir dos primeiros anos da década de 1980, no bojo do processo de democratização do Brasil. Com a expectativa do fim de mudança do regime militar, o clima de transição abria horizontes e perspectivas para que partidos políticos, artistas, intelectuais e gestores da atividade cultural buscassem novos espaços de interlocução por meio do campo da cultura ${ }^{1}$. Aos poucos, crescia a mobilização desses atores no âmbito dos estados e municípios. Diante das oportunidades institucionais que caracterizam o período que antecede o final da ditadura, particularmente a partir de 1982, com as primeiras eleições diretas para os governos estaduais, mudanças nas políticas regionais propiciaram a criação de secretarias de Cultura, bem como de organizações voltadas a discussões de propostas e defesa de novas ideias nessa área.

Os debates em torno das questões culturais intensificam-se durante a Campanha das Diretas Já (1984), particularmente em razão do clima geral de "otimismo" do período. A campanha das Diretas Já tornou-se um movimento aglutinador de inúmeras

* Universidade de São Paulo, São Paulo, Brasil.

1. A criação de novos partidos após 1980, como o PT, PDT e PTB, além do PMDB e PDS, herdeiros, respectivamente, do espólio político e eleitoral do MDB e da Arena, representou uma mudança no desenrolar da dinâmica política brasileira, dando início a novas disputas entre as forças partidárias. 
demandas democratizantes, inclusive ampliando a ideia da incorporação do direito à cultura. Ela contou com a participação de diferentes atores, entre eles, intelectuais e artistas que, direcionados por interesses circunscritos ou de grupos específicos, possuíam capacidade de articulação e interferência no jogo político nacional.

Entretanto, como aponta Ridenti, em um período anterior, que corresponde à chamada "abertura" do regime militar promovida durante o governo Geisel (19741978), a nova ordem da ditadura soube dar lugar aos intelectuais e artistas de oposição (Ridenti, 2012, p. 4). Ainda que a ditadura exercesse um acirrado controle social por meio do aparelho do Estado durante o governo Geisel, intensificou-se a circulação de discussões políticas e culturais entre intelectuais e artistas. Nesse período, também tomou forma no Movimento Democrático Brasileiro (MDB $)^{2}$ o movimento pela anistia aos presos políticos, no qual se engajaram muitos artistas e intelectuais. Da mesma forma, os partidos que se formaram após 1980, e que assumiram uma dimensão nacional, integraram em suas discussões questões voltadas às áreas da comunicação e cultura.

\section{Antecedentes institucionais}

O primeiro estado a criar uma pasta específica para a cultura foi São Paulo. A Secretaria de Cultura do Estado de São Paulo foi criada em 16 de março de 1979, por meio do Decreto n. 13.426, assinado pelo governador Paulo Salim Maluf3. Foi, portanto, um ato discricionário do governador, sem tramitação na Assembleia Legislativa de São Paulo, nem participação da sociedade civil. A Secretaria da Cultura de São Paulo foi precariamente estruturada, a partir de improvisações para dotá-la de quadro pessoal efetivo e de provisões orçamentárias (São Paulo, 2015). Outros estados seguiram o mesmo caminho, criando suas secretarias de Cultura separadas das de Educação, como foi o caso do estado do Paraná motivações que as orientaram foram diversas. O governador do Paraná, Ney Braga, foi reconhecido como tendo desenvolvido uma gestão exitosa no campo da cultura quando foi ministro da Educação, durante o governo Geisel. O caso de São Paulo é mais obscuro, e tudo indica que o decreto que instituiu a Secretaria de Cultura

2. O MDB consistia no único partido de oposição ao governo militar. Com o fim do bipartidarismo ele passou a constituir о РМDB.

3. No dia $1^{\circ}$ de setembro de 1978 , Maluf foi eleito governador de São Paulo pelo Colégio Eleitoral paulista, tendo como vice José Maria Marin. Tomou posse em 15 de março de 1979, concomitantemente com o início do mandato presidencial do general João Baptista Figueiredo.

4. Em 18 de junho de 1979, foi criada pelo Governo do Estado do Paraná a Secretaria de Estado da Cultura e do Esporte - Sece, Lei n. 7169, assinada pelo então governador Ney Braga. 
atendia aos interesses de ampliação da influência política e de resposta a demandas por cargos durante o governo Paulo Maluf.

Independentemente, era visível que ocorria um redirecionamento das ações do poder público estadual no campo cultural, possibilitando a criação de canais mais diretos de interlocução dos governos estaduais com a área. Em Minas Gerais, Tancredo Neves, ao eleger-se governador, nomeou, em 1983, José Aparecido de Oliveira para a recém-criada Secretaria de Cultura de Minas Gerais. Nas eleiçóes para o Congresso Nacional em 1982, Oliveira havia se candidatado a deputado federal na legenda do рмDв. Eleito com mais de 137 mil votos, foi o segundo mais votado da legenda e o quarto em todo o estado. Empossado na Câmara em fevereiro de 1983, no mês seguinte, foi convidado pelo novo governador de Minas a ocupar a pasta da Cultura do estado. No Rio de Janeiro, em março de 1982, seguindo o mesmo movimento, Darcy Ribeiro foi lançado candidato a vice-governador pelo PDT, na chapa vitoriosa encabeçada por Leonel Brizola. Empossado como vice, acumulou no novo governo o cargo de secretário estadual de Ciência e Cultura.

A criação de secretarias de Cultura em estados e municípios da federação possibilitou uma articulação entre secretários e gestores da área, resultando no Fórum Nacional de Secretários de Cultura, que ocorreu em Curitiba em 1983. Poerner (2000) conta que José Aparecido, logo após tomar posse como secretário de Cultura de Minas Gerais em 15 de março de 1983, convidou os secretários estaduais Fernando Ghignone (PR), João Pacheco Chaves (SP) e Darcy Ribeiro (RJ) para um encontro em Ouro Preto, em junho daquele ano, com a presença do senador Afonso Arinos de Melo Franco e do então embaixador da França no Brasil, Robert Richard, uma vez que o ministério da Cultura francês era uma pasta de prestígio e ocupada por Jack Lang, uma personalidade conhecida e arrojada nos meios intelectuais. Conforme Poerner, a intenção de José Aparecido era possibilitar a criação de um "instrumento permanente de mobilização de recursos e de vontades para um programa nacional de trabalho, cuja meta síntese era a criação do Ministério da Cultura” (Oliveira, ver Poerner, 2000, p. 40).

Duas reuniões preparativas foram realizadas para a formalização do Fórum: a primeira, em São Paulo, em agosto, com a participação de secretários e técnicos de diversas áreas da ação cultural; a segunda foi o Encontro Nacional de Dirigentes de Educação, Cultura e Desporto, promovido pelo MEC em Brasília, em setembro. Nesta última, deliberou-se pela institucionalização do Fórum, o que ocorreu dois meses depois. Realizado em Curitiba, nos dias 11 e 12 de novembro de 1983, o I Fórum Nacional de Secretários da Cultura reuniu representantes de treze estados (ao núcleo inicial de Ouro Preto agregaram-se os secretários de Mato Grosso do Sul, Goiás, Maranhão, Amapá, Piauí, Pará, Sergipe, Santa Catarina e Amazonas), que aprovaram um regimento para o novo órgão (Poerner, 2000, p. 40). 
Esses encontros definiram os objetivos e atribuições do Fórum, que teria caráter permanente em função consultiva e de recomendação, além das seguintes finalidades: formular diretrizes básicas de uma política cultural comum; reunir esforços, captar recursos e organizar meios para as políticas e atividades nas diversas áreas da cultura, visando ao intercâmbio no plano nacional e à obtenção do apoio federal; procurar as ações integradas para maior apoio e difusão de manifestações culturais que ocorrem no Território Nacional, respeitando-se as características heterogêneas de Estados e regiões; fortalecer as expressões e manifestações criativas que reafirmem a identidade cultural nacional. (Curitiba, ver Poerner, 1983, p. 135). Nota-se que os objetivos gerais acordados no Fórum atestavam o caráter político da proposta.

Em 1983, a criação do Fórum Nacional de Secretários da Cultura foi articulada por José Aparecido de Oliveira, um exímio operador dos bastidores da política. $\mathrm{O}$ Fórum foi transformado em instância de poder e em instrumento permanente de mobilização para a criação do MinC, sob o argumento central de que era necessário instituir uma ação aglutinadora do setor dentro da nova ordem democrática que se desenhava.

\section{A aliança política para a criação do MinC}

Em 21 de abril de 1984, o Fórum Nacional de Secretários da Cultura promoveu o I Encontro Nacional de Política Cultural. O encontro foi realizado em Ouro Preto e teve prosseguimento no Palácio das Artes, em Belo Horizonte. Entre os participantes, estavam presentes os secretários da Cultura de dezesseis estados e de um território, segmentos da sociedade civil, entidades de classe, estudantes, produtores e consumidores de cultura, além de representantes da Unesco e da Secretaria de Cultura do MEC e expoentes da inteligência brasileira. Para Santayana (2000), esse encontro correspondeu a uma retomada da aliança entre a ação política e a intelligentsia:

\footnotetext{
Quase todas as intervenções, com uma linha ou outra de raciocínio, seguiam a ideia geral de que o poder faz a cultura, e a cultura estabelece o poder. Do encontro participaram figuras angulares no pensamento nacional, como Celso Furtado, Darcy Ribeiro, Ferreira Gullar, Carlos Castello Branco, Millôr Fernandes, Cláudio Abramo, Abdias do Nascimento, entre outros (Santayana, ver Poerner, 2000, p. 10).
}

Conforme Santayana, José Aparecido de Oliveira mirava a criação do Ministério da Cultura, a exemplo do que ocorria na França sob Jack Lang. Para o autor, a ideia de um ministério autônomo para a cultura ganhava força entre os intelectuais (Idem, p. 10). 
As resoluções finais do I Encontro Nacional de Política Cultural promovido pelo Fórum Nacional de Secretários de Cultura enfatizavam que o caráter aberto e democrático das reunióes havia possibilitado a ampla discussão das diretrizes e objetivos da política cultural dos poderes públicos federal, estadual e municipal. $\mathrm{O}$ documento apontava que os debates ocorridos no encontro acentuaram que a União não cumpria seu dever constitucional de amparo à cultura e vinha, deliberadamente, relegando-a a um plano inferior entre seus projetos prioritários. Assinalava, ainda, que a minimizada participação dada à cultura no Plano Nacional de Desenvolvimento manifestava-se nos parcos recursos financeiros e humanos que lhe eram destinados $\mathrm{e}$ no alijamento dos grupos sociais, especialmente os étnicos. Os presentes no encontro reconheciam também a necessidade de criação do Fundo Nacional de Desenvolvimento da Cultura, a exemplo de outros já existentes, como o Fundo Nacional de Desenvolvimento Científico e Tecnológico e o Fundo Nacional de Desenvolvimento da Educação, cujos recursos deveriam ser repassados da esfera federal aos estados e municípios, que melhor os canalizariam, dada sua maior proximidade com as realidades locais. $\mathrm{O}$ documento afirmava, por fim, que não mais cabia à União a tutela da cultura brasileira (Belo Horizonte, ver Poerner, 1984, p. 137).

A edição de 20 de abril de 1984 do jornal $O$ Globo publicou matéria intitulada “Minas abre amanhã Encontro Nacional de Política Cultural”. Descrevia a matéria que o 21 de abril daquele ano não seria apenas o ponto alto das comemorações da Semana da Inconfidência, como, tradicionalmente, ocorria no Brasil Republicano, pois, em Ouro Preto, além de saudar a memória dos inconfidentes, o governador Tancredo Neves faria a abertura oficial do I Encontro Nacional de Política Cultural. Durante quatro dias, gestores da atividade cultural no Brasil estariam reunidos para um debate com a mais ampla gama de produtores e estudiosos do fenômeno cultural do país.

Na matéria, o secretário de Cultura de Minas, deputado José Aparecido de Oliveira, presidente do Fórum Nacional de Secretários de Estado da Cultura e promotor do Encontro Nacional, afirmava que em momentos de grave crise a nação buscava, em uma profunda reflexão sobre sua cultura, a carteira de identidade nacional, que daria o tom da resistência e mostraria os caminhos da construção de um novo tempo. Ainda de acordo com a matéria, Aparecido reconhecia que o fenômeno cultural possuía amplitude acima dos partidos. Por essa razão, afirmava que a relação entre os participantes do I Encontro Nacional de Política Cultural era de caráter ecumênico: dele participariam tanto o secretário de Cultura do MEC Marcos Vinícios Vilaça, como o secretário e vice-governador do Rio Darcy Ribeiro, representando governos de orientação político-partidária completamente oposta. Estariam reunidos também os secretários de Cultura de praticamente todos os estados, fossem do PDS ou do 
PMDB. A matéria apontava, ainda, que o evento abordaria assuntos diversos, como: preservação do patrimônio histórico e arqueológico, humor na cultura brasileira, novas técnicas de comunicação, identidade nacional, a intervenção do Estado na cultura, fontes alternativas de financiamento cultural, entre outras. Essas temáticas eram as principais preocupações que seriam enfrentadas pelas mesas de debates. Entre os presentes estariam o cartunista Henfil, o escritor Austregésilo de Athayde, o empresário José Mindlin e a atriz Fernanda Montenegro, revelando o arco de apoios mobilizados e a envergadura dos convidados (O Globo, 1984, p. 21).

Para José Aparecido, a proposta de criação do Ministério da Cultura era condição sine qua non para a solução dos problemas orçamentários enfrentados pela área; a questão orçamentária era a forma como justificava a necessidade urgente de uma pasta autônoma para o setor. Em depoimento à jornalista Sônia Biondo publicado no jornal $O$ Globo, em 28 de março de 1984, José Aparecido fazia a seguinte observação:

Um problema grave da área cultural é que os orçamentos do Ministério da Educação e Cultura apenas são repassados para as Secretarias estaduais, através de um convênio anual com as Secretarias de Educação. Não acho que se deva tirar verba da Educação para a Cultura. O que proponho é que o MEC se divida em dois ministérios - um para cada assunto (Oliveira, ver Biondo, 1984, p. 29).

Na mesma matéria, José Aparecido enfatizava a necessidade de maior participação da cultura no orçamento global do MEC:

Se em matéria de recursos humanos já não somos tão insuficientes, somos carentes, em grau desesperador, de recursos financeiros. Em países como o nosso, nos quais ainda não se considera a cultura um bem de produção, esses recursos não podem vir de ações aleatórias de mecenas. A cultura, ao contrário do que se pensa, é o maior de todos os nossos bens de produção, porque todo progresso material, tecnológico, todo desenvolvimento, é consequência cultural, fruto direto da dimensão do saber (Idem, p. 29).

Desse modo, os encontros promovidos pelo Fórum, particularmente durante os anos de 1983 e 1984, estimularam os debates sobre políticas culturais, financiamento da cultura, integração de ações entre a federação, estados e municípios, expansão dos meios de comunicação e nacionalização da cultura. Mas, para além disso, esses eventos serviram, fundamentalmente, como espaços políticos de articulação para a criação do MinC. É preciso enfatizar que eles só podiam acontecer porque o regime militar perdera força, e havia um processo corrente de recomposição de forças sociais em prol da luta política de democratização do país. 
Para Ângelo Oswaldo, ex-presidente do Iphan, nesses encontros havia um grande entusiasmo por conta dos temas trazidos para discussão:

\begin{abstract}
As reuniões do Fórum de Secretários serviam para estimular o debate, mas houve muitas outras reuniões. Na verdade, toda a classe artística, os meios intelectuais e acadêmicos, a juventude, com movimentos diversos das comunidades, se mobilizava em torno da política pública de cultura, do debate cultural e da necessidade da cultura. E a cultura apareceu, naquele momento, como o grande espaço de convergência dos movimentos democráticos (Silva e Midlej, 2001, p. 23).
\end{abstract}

As eleições indiretas de 1984: o MinC em pauta

O empenho e a articulação de José Aparecido de Oliveira junto ao Fórum e o forte apoio do РMDB em torno da ideia eram secundados por outro candidato à presidência da república: o PDS de Paulo Maluf tomou carona nos debates sobre a criação do Ministério da Cultura e o assumiu como programa de campanha nas eleições presidenciais indiretas de 1984, proposta que tanto explicita a mobilização política do assunto como esclarece parte das motivações do político paulista, quando foi pioneiro na criação da pasta da Cultura, o que revela o significado das iniciativas como moeda de troca no âmbito das disputas eleitorais; atesta também a tentativa de aproximação com atores muito presentes e influentes nos meios de comunicação. Paulo Maluf, especialmente, não era simpático ao setor artístico e intelectual.

Conforme um crítico do jornal Folha de S.Paulo, em maio de 1984, Paulo Maluf manifestou seu desejo de criar o Ministério da Cultura, caso saísse vencedor da convenção do PDS em setembro e da votação indireta do Colégio Eleitoral (Coelho, 1984, p. 33). De acordo com a matéria, o pianista João Carlos Martins, ex-secretário estadual da Cultura de São Paulo, havia apresentado uma série de sugestões a Maluf, enfatizando que os planos elaborados durante sua gestão poderiam ser transplantados para o novo ministério. Para Martins, Maluf havia ficado entusiasmado com a ideia e também concordara em conceder $0,5 \%$ de dedução do imposto de renda a pessoas físicas e jurídicas que destinassem verbas para a cultura. Grandes empresas poderiam aprovar projetos culturais próprios junto a um conselho e pessoas físicas contribuir para o Banco Nacional da Cultura, que seria responsável por receber as doações (Idem, ibidem).

Entretanto, não havia consenso entre os partidos políticos, intelectuais e artistas em torno da ideia de criação de um ministério autônomo para a cultura. No que diz respeito a artistas e intelectuais, conforme relatos publicados na grande imprensa, muitos deles eram contrários à ideia de criação do $\mathrm{MinC}$ e argumentavam que uma 
pasta para a cultura não correspondia às necessidades prementes da nação, que a separação entre educação e cultura traria sérios prejuízos, além de custosa manutenção da burocracia estatal que requeria um ministério. No entanto, temiam acima de tudo a intervenção do Estado na cultura.

Em 7 de outubro de 1984, a colunista Norma Couri relatava em matéria publicada no jornal Folha de S.Paulo que não existia consenso sobre a criação do ministério. Para alguns artistas e intelectuais consultados por Couri, a criação do MinC parecia ser a decisão mais apropriada para resolver a falta de recursos financeiros e de autonomia política enfrentada pela área cultural. Para outros, a criação do ministério não era uma demanda da própria sociedade; estes ainda alertavam para o perigo de intervenção e controle do Estado na cultura. Alegavam que a criação do MinC era prematura, apontando que o país era muito pobre para ter um Ministério de Estado específico para a cultura e que, fundamentalmente, a separação entre cultura e educação traria prejuízos, entre outras razões, pela divisão orçamentária das duas pastas (Couri, 1984, p. 10).

Pietro Maria Bardi, diretor do Museu de Arte de São Paulo Assis Chateaubriand (Masp), concordava com a criação do Ministério, desde que a cultura defendida pela pasta não fosse a popular. O escritor Marcio de Souza apoiava Bardi, mas achava que a ideia de Darcy Ribeiro de defesa da cultura do popular representava um atraso. Por sua vez, a atriz Ítala Nandi, fundadora do Teatro Oficina e militante do PCB, mostrava-se totalmente contrária à ideia de uma pasta para a cultura. Da mesma forma, o escritor Antônio Callado achava o Brasil muito pobre para ter um ministério da Cultura. O secretário de Cultura de São Paulo Jorge Cunha Lima era contra a criação do ministério porque a cultura deixaria de ser um apêndice da educação, mas ficaria atrelada à ciência e à tecnologia (Idem, p. 10). Enfim, as diferentes posições exprimem orientações e crenças políticas, mas exemplificam, igualmente, interesses específicos, como o caso do diretor do Masp.

O filólogo comunista Antônio Houaiss julgava que a criação do MinC representava uma fantasia maléfica, já que os recursos financeiros seriam divididos entre educação e cultura. O poeta Carlos Drummond de Andrade, conhecido por seu apartidarismo político, também era contrário à ideia de um ministério específico para o setor, não porque temesse o controle do governo, mas por considerar a superestrutura da cultura muito frágil para que se criasse toda uma burocracia para abarcá-la (Idem, ibidem).

Vale ressaltar outras declarações de significativa importância apresentadas por Norma Couri. Conforme a colunista, o professor e poeta Décio Pignatari, fundador do concretismo e à época membro do $\mathrm{PCB}$, entendia como positiva a criação do MinC, mas alertava para a necessidade de uma melhor articulação entre cultura e educação. 
Para Pignatari, alguma vinculação com a educação era necessária. Ele observava ser necessário que a criação desse ministério não viesse para ditar normas culturais, mas somente para financiar programas criativos. O compositor, pianista e cantor Arrigo Barnabé achava que a discussão não valia a pena, e o artista plástico paulista Wesley Duke Lee mostrava-se contra o patrocínio da cultura pelo governo. Por sua vez, o dramaturgo Dias Gomes e o cineasta Luiz Carlos Barreto, os dois militantes do РСB, eram favoráveis à criação de um ministério para a cultura ${ }^{5}$. Tancredista, o humorista, escritor e desenhista mineiro Ziraldo também acreditava que a cultura deveria ser tratada no âmbito de um ministério. Do mesmo modo, o artista plástico cearense Aldemir Martins confirmava a necessidade de criação do MinC (Idem). Percebe-se que as discrepâncias de opinião também resultavam da natureza do vínculo profissional e da inserção no mercado da cultura.

Também na Folha de S.Paulo, o jornalista Matinas Suzuki Júnior, em 30 de dezembro de 1984, manifestou não só sua preocupação com a criação do Ministério da Cultura, mas o quanto o considerava desnecessário:

Note-se, ainda, que o período pós- 64 assistiu a um acentuado avanço do capital cultural, e
o mercado de bens simbólicos dinamizou a sua racionalidade produtiva; registrou-se um
processo avançado de profissionalização que uma visão arcaica do desempenho do Estado na
economia do "supercapitalismo" só vai conduzir a medidas demagógicas e ao pragmatismo
regressivo. De resto, é preciso entender que a formulação benjaminiana de que todo docu-
mento de cultura é também um documento de barbárie se refere inclusive a esta temporada
pós-ditadura que estamos inaugurando. Ionesco dizia que um ministro da Cultura deveria
existir apenas para dar papel e caneta para escritores, tintas e pincéis para pintores etc. (Suzuki
Júnior, 1984, p. 3)

Para entender o posicionamento do jornalista, cabe lembrar os efeitos do regime pós-64 sobre a produção cultural no Brasil. Como aponta Miceli, no período da ditadura militar, à sombra do apoio do Estado, a iniciativa privada florescia, e as melhores oportunidades de investimento e faturamento na atividade cultural passavam longe do setor público. Os grandes empreendedores particulares exploravam as conveniências de investimento naquelas atividades e frentes de expansão capazes de garantir as mais altas taxas de retorno sobre o capital (Miceli, 1984b, pp. 27-31).

5. Note-se que esse posicionamento favorável estava ligado a áreas culturais que exigem financiamento.

6. Matinas Suzuki Junior assim como Otavio Frias participaram da reforma editorial da Folha de S.Paulo comandada por Cláudio Abramo, que abriu espaço para artistas e intelectuais se expressarem no veículo (Ferron, 2017). 


\section{A oposição ao MinC de intelectuais da nova esquerda}

Em 6 de janeiro de 1985, Norma Couri relatava em matéria no jornal Folha de S.Paulo que, assustados, ansiosos ou neutros, intelectuais e artistas brasileiros discutiam a criação de um Ministério da Cultura e, mais que isso, os caminhos a serem seguidos pela cultura no novo governo que se anunciava. Alguns intelectuais e artistas detectavam o risco do paternalismo e do autoritarismo; outros sentiam falta de uma política cultural mais definida e queriam a criação de um Ministério da Cultura.

Couri revelava que a deputada Ruth Escobar, que, em 1978, havia entrado no MDB e fora eleita deputada estadual pelo PMDB em 1982, esquivava-se e evitava dar uma opinião, afirmando que o tema era tão complexo que só poderia ser abordado após um estudo sobre os verdadeiros anseios da sociedade civil. A professora de filosofia Marilena Chaui, crítica do populismo de direita e de esquerda e das tutelas estatais, afirmava que por questão de princípio era totalmente contrária à criação de um Ministério da Cultura. Marilena enumerava três motivos: "Primeiro: cultura não se deve administrar; segundo: a criação de um ministério vai trazer mais burocracia, e burocracia não é um estímulo para a cultura, e terceiro: um ministério significa novos encargos fiscais. Como contribuinte, não quero pagar mais impostos" (Chaui, ver Couri, 1985, p. 12).

Marilena Chaui, Antonio Candido, Florestan Fernandes, Otávio Ianni, Lélia Abramo e outros intelectuais e artistas que representavam o PT (partido formado pela confluência de diversos grupos de esquerda), por serem abertamente refratários à esquerda tradicional ${ }^{7}$, eram contrários à criação do ministério. Desconfiavam do papel "progressista" das vanguardas intelectuais, elaborando uma crítica a respeito de tais concepções. Conforme a análise de Ridenti, os anos de 1970, tanto no campo da política como da cultura de esquerda, são marcados pelo fim do "ciclo das

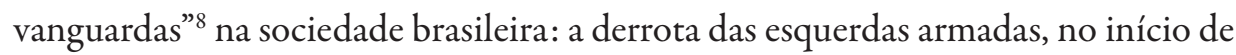
1970, deu início a um novo ciclo marcado na política de esquerda pelo surgimento do Partido dos Trabalhadores (PT) (Ridenti, 2012, p. 1).

7. A esquerda tradicional era representada pelo Partido Comunista Brasileiro ( $\mathrm{PCB})$, conhecido como Partidão.

8. Para Ridenti: "O termo vanguarda (avant garde) tem uma relação com os combates militares em que alguns avançam, colocam-se à frente, enquanto outros ocupam a retaguarda. No sentido político, a concepção de vanguarda é tributária dos bolcheviques, vitoriosos na Revolução Russa de 1917: o Partido - organizado de modo secreto e centralizado - propunha-se como a vanguarda condutora das lutas do proletariado, sua organização política, detentor da análise científica da História, formulador da consciência de classe revolucionária atribuída aos trabalhadores. No âmbito das artes, a noção de vanguarda também tem um aspecto de combate, capitaneado por aqueles que seriam portadores do novo em ruptura revolucionária com a ordem artística estabelecida" (Ridenti, 2012, p. 1). 
Em depoimento a um dos autores deste artigo, Marilena Chaui revelou os motivos que levaram o PT a rejeitar a ideia de criação do ministério. A filósofa destacou que, em relação às formulações de políticas culturais, o PT colocava-se contrário à ideia de o Estado produzir e dirigir cultura:

Primeiro, nós fizemos a oposição à criação do Ministério: "não vão criar o Ministério da Cultura”. Nós somos contra o Estado dirigindo a cultura, produzindo a cultura! Criaram o Ministério. Uma vez criado o Ministério e a partir do momento em que se têm políticas culturais estaduais e municipais, você vai dizer: "Bom, que haja também no plano federal, por que não?". Mas não é esse o ponto, o ponto é: se o Collor fechasse o ministério, ele estaria demostrando que ele não possuía quadros, que ele era incompetente, que ele não podia ter sido eleito, então nós lutamos para impedir que fechasse. Foi uma luta política, não uma luta cultural. Contra a criação do ministério foi uma luta cultural, de política cultural, era a defesa de uma concepção - que é a sociedade que produz cultura e não o Estado. No caso do Collor não, foi uma atitude claramente política: nós tínhamos que fazer que ele demonstrasse que não possuía quadros, que ele era incapaz de compreender o campo da cultura. (Chaui, 2017).

A declaração de Marilena Chaui é um exemplo de como a criação do MinC passou a ser pauta das disputas políticas e de poder.

\section{5: O Seminário Internacional de Legislação Cultural}

Em março de 1985, com o presidente Tancredo Neves já eleito e diante da perspectiva de anúncio da criação do MinC, acirra-se o debate entre políticos, artistas, gestores e empresários sobre a necessidade de uma pasta para a cultura. Uma matéria publicada no jornal Folha de S.Paulo, em 9 de março daquele ano, relatava fatos ocorridos durante o Seminário Internacional de Legislação Cultural, que havia sido realizado dias antes no Hotel Maksoud Plaza, em São Paulo. Conforme a matéria, o evento contara com a presença de personalidades da política, como o vice-presidente eleito José Sarney, o senador Fernando Henrique Cardoso, além de artistas, gestores, empresários e convidados internacionais. A matéria apontava a forte dissidência de ideias entre eles. O evento foi iniciado com a mesa "Empresa e cultura" e terminara com outra mesa, que debateu "Cultura e liberdade de expressão" (Folha de S.Paulo, 1985).

De acordo com a matéria, o secretário de Cultura de São Paulo Jorge da Cunha Lima (1983-1987), ao tomar a palavra, lembrou os vinte anos de indigência cultural e os 30 milhões de brasileiros afastados da produção cultural pelo estado de miserabilidade em que ela se encontrava. A fala do vice-presidente eleito José Sarney teria provocado olhares desconfiados, uma vez que ele afirmava ser necessário combater 
tecnocratas e economistas. Sarney discorreu sobre a necessidade do ministério, o que conforme o vice-presidente evitaria que o artista fosse obrigado a sair com um pires na mão esmolando favores de boa vontade; tratava-se de defender direitos culturais (Idem).

O economista Luiz Carlos Bresser Pereira observou que a cultura poderia ser traduzida por uma série de serviços que poderiam ser pagos por alguém, mais especificamente, o público, e não o Estado ou empresas privadas. Para ele, as empresas poderiam patrocinar eventos culturais, desde que recebessem um retorno. Logo após suas afirmações, Bresser Pereira retirou-se dos debates, provocando a ira de Fafá de Belém, que, ao lado de Juca de Oliveira, Raul Cortez e Irene Ravache, representava a classe artística. Para Fafá de Belém, Bresser sempre se posicionava como progressista, mas naquele momento estava sendo reacionário (Idem, p. 45).

A matéria mencionava ainda que Juca de Oliveira, militante do РCB, ao falar em nome da União Brasileira de Teatro, teria sido taxativo ao denunciar o monopólio das emissoras de televisão, observando que não era possível discutir um projeto cultural sem eliminar o monopólio das redes de televisão. De acordo com a matéria, ele propôs a formação de uma comissão com representantes sindicais e do Legislativo para discutir a programação ao vivo das emissoras de TV (Folha de S.Paulo, 1985a, p. 45). Ao enfatizar a questão do monopólio das emissoras de televisão, Juca de Oliveira endereçava sua crítica ao poder da indústria cultural $^{9}$ televisiva que, conforme o ator, não deixava espaço para o reconhecimento da autonomia dos produtores culturais independentes.

Fernando Henrique Cardoso foi aplaudido quando expôs sobre o tema "Cultura e liberdade de expressão”. Ele teria se posicionado com cautela quanto à criação de um Ministério da Cultura, afirmando: "Se for para ampliar o espaço e a participação para a cultura e a liberdade da expressão, ótimo. Mas se for para burocratizar, será um perigo" (Fernandes, ver Folha de S.Paulo, 1985, p. 45). Nota-se que a cautela e a posição conciliatória deixavam o sociólogo bem com todas as vertentes de opinião.

9. Ridenti analisa o florescimento da indústria cultural nos anos de 1970, em todos os seus setores, destacando sua relevância e seu papel crucial no país: "A partir dos anos de 1970, concomitante à censura e à repressão política, ficou evidente o esforço modernizador que a ditadura já vinha esboçando desde a década de 1960, nas áreas de comunicação e cultura, incentivando o desenvolvimento capitalista privado ou até atuando diretamente por intermédio do Estado. As grandes redes de TV, em especial a Globo, surgiam com programação em âmbito nacional, estimuladas pela criação da Embratel, do Ministério das Comunicações e de outros investimentos governamentais em telecomunicações, que buscavam a integração e a segurança do território brasileiro. À sombra de apoios do Estado, floresceu também a iniciativa privada: criou-se uma indústria cultural, não só televisiva, mas também fonográfica, editorial (de livros, revistas, jornais, fascículos e outros produtos comercializáveis até em bancas de jornal), de agências de publicidade etc." (Ridenti, 2012, p. 4). 
Convidado para a mesma mesa, o cantor e compositor Gilberto Gil teria provocado muita agitação com sua presença. Antes de sentar-se, disse aos repórteres que não esperava nada pessoalmente sobre a criação de um ministério feito a "toque de caixa". Na mesa, porém, passou a palavra aos demais participantes e pediu liberdade de silêncio, o que decepcionou a plateia e provocou a pergunta de uma participante: "Se você pode falar e não fala o que será de nós?”. Foi então que aconteceu a primeira ovação unânime da plateia (Idem, ibidem). Tal como disposto acima, as posições defendidas por diferentes atores sinalizavam naquelas condições históricas os esforços em repensar as condições de produção cultural brasileira, reanimada pela proximidade de redemocratização do país. Os debates mostravam, em síntese, que a questão estava longe de unanimidade, mas mobilizava pessoas de diversos espectros.

\section{O governo Sarney: a criação do MinC}

Os contornos dos debates ocorridos por ocasião do Seminário Internacional de Legislação Cultural emaranhavam-se muito com o próprio momento histórico e com a tônica de reivindicações democráticas. É preciso lembrar que o país esperava a posse de Tancredo Neves, em 15 de março de 1985, como o primeiro presidente civil eleito desde o golpe militar de 1964. Tancredo, entretanto, foi internado às vésperas da posse, e José Sarney assumiu a presidência.

No dia da posse, o MinC foi criado por meio do Decreto n. 91.144, publicado no Diário Oficial da União em 15 de março de 1985. A justificativa de Sarney para a criação do Ministério da Cultura era honrar os compromissos assumidos, tanto pelo presidente Tancredo Neves como por ele durante a campanha eleitoral. $\mathrm{Na}$ introdução do texto do Decreto n. 91.144, a importância da criação do Ministério da Cultura é justificada por meio de quatro razóes:

1. O crescimento econômico e demográfico do país, a expansão da rede escolar e universitária, a complexidade cada vez maior dos problemas ligados à política educacional, nas suas diferentes funções no desenvolvimento nacional, bem como o enriquecimento da cultura nacional, decorrente da integração crescente entre as diversas regiões brasileiras, e da multiplicação das iniciativas de valor cultural, tornavam a estrutura orgânica do Ministério da Educação e Cultura impossibilitada de exercer, concomitantemente, as requisições dos dois campos de sua competência naquele momento;

2. A transformação substancial ocorrida nas últimas décadas, tanto em relação aos assuntos educacionais quanto aos assuntos culturais, suscitava, em relação às duas áreas, a necessidade de métodos, técnicas e instrumentos diversificados de reflexão e administração, 
e exigia políticas específicas bem caracterizadas, que reclamavam o desmembramento da atual estrutura unitária em dois ministérios autônomos;

3. Os assuntos ligados à cultura nunca puderam ser objeto de uma política mais consistente, em razão da vastidão da problemática educacional que atraiu sempre a atenção preferencial do Ministério;

4. A situação atual do Brasil não pode mais prescindir de uma política nacional de cultura, consistente com os novos tempos e com o desenvolvimento já alcançado pelo país. (Brasil, 1985). (citação)

O Decreto n. 91.144, entretanto, não indicava claramente qual o âmbito de atuação do Mistério da Cultura; destacava apenas dois tópicos bastante gerais, que se referiam às áreas de sua competência: I - letras, artes, folclore e outras formas de expressão da cultura nacional; II - patrimônio histórico, arqueológico, artístico e cultural (Idem).

O novo ministério criado por Sarney continuava a suscitar debates e seria merecedor de apreciações de importantes intelectuais. Em matéria publicada em maio de 1985, no jornal Folha de S.Paulo, o jornalista Ruy Castro descreveu a reação de alguns intelectuais à criação da nova pasta. Para Castro, o sociólogo Otávio Ianni considerava que o poder público não possuía compromisso com a cultura e a criação do ministério era a prova disso. Ainda conforme Castro, Florestan Fernandes achava possível a conciliação de uma "política cultural” com um governo democrático, mas não estava nada otimista em relação ao novo ministério. Para o sociólogo, o novo ministério só serviria para distribuir empregos, quando se deveria priorizar uma campanha de alfabetização maciça:

\footnotetext{
Não temos ainda nem um regime democrático. Além disso, no Brasil o Executivo é tradicionalmente centralizador. E as elites culturais estão sempre afinadas com a dominação cultural. O que acontecerá com esse ministério é que, numa primeira etapa, ele só servirá para distribuir empregos entre a classe média alta, quando o que se deveria fazer seria uma campanha de alfabetização maciça. Como se vê, estamos fazendo o caminho inverso (Fernandes, ver Castro, 1985, p. 49).
}

O jornalista e escritor Antônio Callado opinava de forma radicalmente contrária à criação do MinC:

Esse ministério é supérfluo. Com tantos analfabetos adultos e crianças estamos preocupados com a superestrutura da educação, que é cultura. Sou contríssimo. O que precisamos é de projeto. Antigamente, tínhamos a educação e a saúde num mesmo ministério. Foram separados, 
numa medida acertada, mas continuamos até hoje com uma taxa gigantesca de analfabetismo e tuberculose. Agora se separa a cultura da educação (Callado, ver Castro, 1985, p. 49).

Callado, que era amigo pessoal de Oscar Niemeyer, achava que não era hora de o arquiteto projetar um prédio para o Ministério da Cultura, acrescentando o seguinte argumento: "Todo ministro precisa de dinheiro para trabalhar, e eu temo que esse ministério se torne excessivamente gastador" (Callado, ver Castro, 1985, p. 49).

Particularmente em relação a intelectuais e artistas que militavam no Partido Comunista Brasileiro, não houve unidade no apoio à criação de uma pasta separada para a cultura. Alguns apoiaram a ideia, mas a maioria, que declarou sua opinião à imprensa, mostrou-se francamente contrária à criação do ministério. Tal fato, possivelmente, decorria de que os anos de 1980 significaram para o PCB não só a saída de Prestes ${ }^{10}$, mas de um grande número de intelectuais que passaram a integrar o Partido dos Trabalhadores (PT). Em relação ao PT e ao PMDB, ainda que existissem divergências internas, a decisão tomada por seus membros foi amplamente acatada. O PT adotou uma posição contrária à criação do MinC e o PMDB favorável.

\section{Montagem do ministério}

Apesar das controvérsias no meio partidário sobre a conveniência ou não de um ministério para a cultura, a escolha do nome de José Aparecido de Oliveira para ocupar o cargo de ministro da Cultura era certa. Sua militância junto ao Fórum Nacional de Secretários de Cultura legitimava a indicação para a pasta, que, aliás, tinha sido projetada pelo próprio ministro. Para Botelho, os técnicos da área federal não compartilhavam da ideia de criação do MinC. Segundo a autora, eles preferiam "uma secretaria forte a um ministério fraco" (Botelho, 2000, p. 45). Entretanto, a militância dos secretários estaduais de cultura, sob a liderança de José Aparecido, transformou a criação da pasta em sinônimo de democracia, o que tornou inexequível qualquer discussão mais isenta sobre sua necessidade (Idem, ibidem).

Ruy Castro (1985) apontou que, antes mesmo de sua previsível vitória no colégio eleitoral, Tancredo teria afirmado: "Precisamos arranjar um ministério para o Aparecido" (Neves, ver Castro, 1985, p. 49). Para Castro, tratava-se de uma dissimulação de Tancredo, pois era evidente que o ministério que caberia ao deputado era o da Cultura. A criação do MinC, que serviu politicamente ao velho aliado do futuro presidente, nunca chegou a ser bem discutida. Para o jornalista, os que poderiam "discutir" a razão de ser do novo ministério não viam motivo para contestar a indi-

10. Em janeiro de 1984, Prestes desligou-se oficialmente do РСв. 
cação de Aparecido ou contradizer uma "decisão de Tancredo" (Castro, 1985, p. 49).

Contudo, apesar da experiência política que garantiu a liderança de José Aparecido no processo de criação do MinC, esses atributos não foram suficientes para que a nova pasta fosse instituída com estrutura administrativa e orçamentária, capaz de responder à demanda contida dos gestores culturais. Com estrutura administrativa mínima e sem dotação de verbas, o MinC nasceu sem recursos materiais e humanos. Por essa razão, entende-se por que, em menos de seis meses, em 29 de maio de 1985, José Aparecido deixou o ministério, passando a ocupar o cargo de governador do Distrito Federal, pois seu exercício lhe renderia maior benefício político. Além disso, quando da criação do MinC, o lobby exercido pelo MEC impediu que rádios e televisões ${ }^{11}$ educativas ficassem sob a jurisdição do Ministério, exatamente os veículos que trariam visibilidade à área e aos ocupantes (Castro, 1989, p. 32).

Para muitos autores, a forma prematura como foi criado o MinC acarretou toda uma série de problemas. Botelho faz a seguinte observação:

Espero ter demonstrado que a criação prematura do Ministério, baseada em premissas alheias às efetivas necessidades naquele momento, ao invés de reforçar o prestígio e a consistência da área, foi, ao contrário, fator de desarticulação e desmoralização. O principal motivo do fracasso foi, no meu entender, o papel preponderante do jogo da política miúda que descaracterizou conteúdos, reduzindo o debate a uma disputa interna (Botelho, 2000, p. 265).

Botelho aponta, ainda, que o comando carismático do deputado José Aparecido de Oliveira, que conduziu o secretário de estado a uma bem-sucedida batalha para a criação do MinC, terminou por franquear um espaço excessivo para ambições pessoais de alguns, colocando a cultura na condição de mero pretexto, afetando o projeto desde seu nascimento (Idem, p. 263).

Durand também faz duras críticas ao processo de criação do Ministério, tecendo as seguintes observações:

A propósito, comenta-se no Brasil que, nos anos 80, a passagem da Cultura do nível de Secretaria do Ministério da Educação à condição de Ministério autônomo teria sido antes um subterfúgio para o então Presidente da República, José Sarney, aumentar o espaço de ação de um aliado político, do que propriamente a ampliação de poder institucional necessária

11. Em depoimento ao pesquisador, o ex-secretário estadual de Cultura de São Paulo Marcos Mendonça apontará uma perspectiva complementar a essa questão, afirmando que: "tem outro aspecto que é a separação entre televisão e cinema na política cultural, que foi um erro enorme, porque o pessoal do cinema tinha uma resistência muito grande à televisão, que era vista como entretenimento" (Ferron, 2017). 
para expandir e melhorar essa esfera de ação. Em consequência, não são raros os que avaliam que a situação no Brasil era melhor quando a administração federal da cultura era vinculada à da educação (Durand, 1996, p. 9).

Sem dúvida, as ponderações dos autores mencionados reforçam a ideia de fragilidade do Ministério da Cultura, desde seus primeiros passos. A instabilidade institucional que demarcou esse curto período de existência do MinC pode ser exemplificada pela troca de ministros, por denúncias de corrupção e desmandos. Especificamente em relação à Lei Sarney, duras críticas foram lançadas por Fernando Collor, ainda durante sua campanha, apontando o governo Sarney como conivente com os desmandos praticados na gestão do ministério.

Entretanto, na etapa de transição democrática da política brasileira, quando estavam sendo formuladas importantes mudanças de perspectivas no campo político e cultural, o horizonte constante de discussões sobre a criação de um ministério para a cultura refletia a importância que a área assumia na convergência dos movimentos democráticos. Desse modo, aproveitando o processo de abertura, partidos políticos, artistas e intelectuais colocavam-se na dianteira de tal discussão. $\mathrm{O}$ temor de a cultura ser novamente colocada como instrumento ideológico de controle do Estado, o fantasma da perseguição a artistas e intelectuais, a exemplo do atentado do Riocentro em 1981, das ameaças advindas do crescimento da indústria cultural e da massificação dos meios de comunicação, reverberavam a todo momento. Assim, as polêmicas e divergências em torno da criação do MinC constituem, sem dúvida, parte dos princípios fundantes do processo de redemocratização em curso na sociedade brasileira, bem como das disputas políticas previsíveis no contexto. Tal cenário apresenta componentes inextricáveis à compreensão do projeto e do formato adquiridos pelo Ministério da Cultura do Brasil. 


\section{Referências Bibliográficas}

Arruda, Maria Arminda do Nascimento. (2003), "A política cultural: regulação estatal e mecenato privado". Tempo Social, São Paulo. 15 (2): 177-193. Disponível em http://dx.doi. org/10.1590/S0103-20702003000200007, consultado em 20/1/2018.

Barbalho, Alexandre. (2007), "Políticas culturais no Brasil: Identidade e diversidade sem diferença". Trabalho apresentado no III Enecult - Encontro de Estudos Multidisciplinares em Cultura, 23 a 25 de maio, Faculdade de Comunicação/UfBA, Salvador. Disponível em http://hugoribeiro.com.br/biblioteca-digital/Barbalho-politicas_culturais_no_Brasil.pdf, consultado em 22/3/2017.

Botelho, Isaura. (2000), Romance de formação: Funarte e politica cultural, 1976-1990. Rio de Janeiro, Edições Casa de Rui Barbosa.

Botelho, Isaura. (2007), “A política cultural \& o plano das ideias”. In: BARbALHo, Alexandre \& Rubim, Albino (orgs.). Politicas culturais no Brasil. Salvador, EDUfBA.

Brasil. (1985), Decreto n. 91.144, de 15 de março de 1985. Presidência da República, Casa Civil, Subchefia para Assuntos Jurídicos. Disponível em http://www.planalto.gov.br/ccivil_03/decreto/1980-1989/D91144.htm, consultado em 1/4/2017.

Calabre, Lia. (2007), "Políticas culturais no Brasil: balanço e perspectivas". Trabalho apresentado no III Enecult - Encontro de Estudos Multidisciplinares em Cultura, 23 a 25 de maio, Faculdade de Comunicação-ufba, Salvador. Disponível em http://www.guiacultural. unicamp.br/sites/default/files/calabre_1_politicas_culturais_no_brasil_balanco_e_perspectivas.pdf, consultado em 10/4/2017.

Cardoso, Fernando Henrique. (1989), "Política cultural". Jornal no Brasil. Rio de Janeiro, 16/07, pp. 7-8.

Castro, Luiz Felipe Meira de. (1989), "O estado atual da política cultural no Brasil: Uma agenda de debates". Revista de Administração Pública, 23 (1): 21-35. Disponível em http:// bibliotecadigital.fgv.br/ojs/index.php/rap/article/view/9360, consultado em 26/6/2017.

Chaui, Marilena. (2017), Entrevista concedida a Fabio Maleronka Ferron, em 28 de abril de 2017. Gravada em Mov.

Durand, José Carlos Garcia. (abr.-jun. 1996), "Profissionalizar a administração da cultura”. Revista de Administração de Empresas, 36 (2): 6-11. Disponível em http://www.scielo.br/scielo.php?pid=S0034-75901996000200002\&script=sci_arttext, consultado em 25/3/2017.

Durand, José Carlos Garcia \& Gouveia, Maria Alice; Berman, Graça. (1997), "Patrocínio empresarial e incentivos fiscais à cultura no Brasil: Análise de uma experiência recente”. Revista de Administração de Empresas, 37 (4): 38-44. Disponível em http://bibliotecadigital. fgv.br/ojs/index.php/rae/article/view/37956/36706, consultado em 5/3/2017.

Ferron, Fabio Maleronka. (2017), O primeiro fim do MinC. São Paulo, dissertação de mestrado em estudos culturais, Escola de Artes, Ciências e Humanidades, Universidade de São Paulo. 
Disponível em http://www.teses.usp.br/teses/disponiveis/100/100135/tde-27112017103623/, consultado em 3/2/2018.

Holanda, Heloísa Buarque de \& GonçAlves, Marcos Augusto. (2005), "A ficção da realidade brasileira". In: Adauto, Novaes (org.). Anos 70: ainda sob a tempestade. Rio de Janeiro, Aeroplano/Senac-Rio.

Lamounier, Bolivar. (1991), De Geisel a Collor: o balanço da transição. São Paulo, Edições Loyola.

Mendonça, Marcos. (2017), Entrevista concedida a Fabio Maleronka Ferron. São Paulo, 15 de abril de 2017. Gravada em Mov.

Miceli, Sergio. (1984a), Estado e cultura no Brasil. São Paulo, Difel.

Miceli, Sergio. (1984b), "Teoria e prática da política cultural oficial no Brasil”. Revista de Administração de Empresas, 24, (1): 27-31. Disponível em http://www.scielo.br/scielo. php?pid=S0034-75901984000100002\&script=sci_arttext, consultado em 23/6/2017.

Ortiz, Renato. (1985), Cultura brasileira e identidade nacional. São Paulo, Brasiliense.

Ortiz, Renato. (2006), A moderna tradição brasileira. São Paulo, Brasiliense.

Poerner, Arthur José. (2000), Identidade cultural na era da globalização: política federal de cultura. Rio de Janeiro, Revan.

Ridenti, Marcelo. (jun. 2005), “Artistas e intelectuais no Brasil pós-1960”. Tempo Social: Revista de Sociologia da USP, 17 (1): 81-110. Disponível em http://www.scielo.br/pdf/ts/ v17n1/v17n1a03.pdf, consultado em 19/6/2017.

Ridenti, Marcelo. (2012), "Cultura e política nos anos 1970: o fim do ciclo das vanguardas no Brasil”. Brasa. Brasilian Studies Association. Disponível em http://www.brasa.org/wordpress/ Documents/BRASA_IX/Marcelo-Ridenti.pdf, consultado em 20/1/2018.

Rubim, Antônio Albino C. \& Barbalho, Alexandre B. (orgs.). (2007), Politicas culturais no Brasil. Salvador, Editora da Universidade Federal da Bahia.

Rubim, Antônio Albino C. (2009), "Políticas culturais e novos desafios". Revista Matrizes, 2 (2). Disponível em https://repositorio.ufba.br/ri/handle/ri/1240, consultado em 2/4/ 2017.

Rubim, Antônio Albino C. (2015), "Políticas culturais no Brasil: desafios contemporâneos". In: Calabre, Lia (org.). Politicas culturais: olhares e contextos. Rio de Janeiro/São Paulo, Fundação Casa de Rui Barbosa/Itaú Cultural. Disponível em http://d3nv1jy4u7zmsc. cloudfront.net/wp-content/uploads/2015/05/PoliticasCulturais02_v07.pdf, consultado em 22/6/2017.

Silva, Frederico Augusto B. da \& Midlej, Suylan (2011), Politicas públicas culturais. A voz dos gestores. Brasília, Ipea.

SKidmore, Thomas. (1988), "A lenta via brasileira para a democratização: 1974-1985". In: Stepan, Alfred (org.). Democratizando o Brasil. Rio de Janeiro, Paz e Terra.

Souza, Maria do Carmo C. de. (1988), "A Nova República brasileira: sob a espada de Dâmocles". In: Stepan, Alfred. (org.). Democratizando o Brasil. Rio de Janeiro, Paz e Terra. 
Souza, Valmir. (2012), "Políticas culturais em São Paulo e o direito à cultura”. Políticas Culturais em Revista, 5 (2): 52-64. Disponível em https://rigs.ufba.br/index.php/pculturais/article/ view/6535/4821, consultado em 29/6/2017.

\section{Artigos de jornal}

Biondo, Sônia. (1984), “José Aparecido: A cultura é fator primordial do povo brasileiro". $O$ Globo, 28/3, p. 29.

Castro, Ruy. (1985), “O fantasma da ópera ministerial”. Folha de S.Paulo, 18/5, p. 49.

Coelho, João Marcos. (1984), "Maluf e Martins, cultura a quatro mãos”. Folha de S.Paulo, $30 / 5$, p. 33.

Couri, Norma. (1985), “Cultura-85, um debate que começa”. Folha de S.Paulo, 6/1, p. 12.

O Globo. (1984), "Minas abre amanhã Encontro Nacional de Política Cultural”. O Globo, 20/4, p. 21.

\section{Resumo}

Cultura e política: a criação do Ministério da Cultura na redemocratização do Brasil

Este artigo analisa a criação do Ministério da Cultura, em 1985, por meio da identificação dos principais atores envolvidos, seus interesses e estratégias, bem como examina as posições dos partidos políticos que se pronunciaram a respeito da necessidade de uma pasta para a cultura separada da educação. Pela análise de fontes jornalísticas e entrevistas, relaciona aquele processo com as características particulares do contexto político da época e apresenta as discussões e debates que acompanharam o desenrolar do processo que definiu a criação de uma pasta autônoma para a cultura. Por fim, conclui que, embora o processo de montagem do Ministério da Cultura no governo Sarney tenha sido influenciado pelas vicissitudes políticas do momento e conduzido de modo pouco eficiente, ele foi expressão da remobilização da sociedade civil brasileira em torno de questões de política pública no processo de transição pós-autoritária na primeira metade dos anos de 1980.

Palavras-chave: Cultura; Ministério da Cultura; Intelectuais; Artistas; Políticas Culturais.

\section{Abstract}

Culture and politics: the creation of the Ministry of Culture in Brazil's transition to democracy This article analyzes the creation of the Brazilian Ministry of Culture in 1985 by means of the identification of its main actor's interests and strategies and of the positioning of the political parties on the debate about the need for a specific ministry for Culture separated from the Ministry of Education. By locating this process in the political context of the mid-1980s through the analysis of journalistic fonts and interviews, it also considers the discussions and debates that led to the creation of an autonomous ministry of Culture. It finishes by concluding that even though 
the process of creation of the Ministry of Culture might have been influenced by petty politics and conducted in a haste and rather inefficiently, it was an expression of the remobilization of Brazilian civil society in the transition to democracy in the early 1980s.

Keywords: Culture; Ministry of Culture; Intellectuals; Artists; Cultural Policies.

Texto recebido em 14/03/2018 e aprovado em 21/05/2018.

DOI: 10.11606/0103-2070.ts.2019.144335

FABIO MALERONKA FERRON é doutorando em sociologia da cultura na Universidade de São Paulo.E-mail: fabiomaleronka@gmail.com.

MARIA ARMINDA DO NASCIMENTO ARRUDA é professora titular do Departamento de Sociologia da Universidade de São Paulo. E-mail: fsl@usp.br. 